\title{
Sodium hyaluronate in the treatment of dry eye after cataract surgery: a meta-analysis
}

\author{
Yan Wen ${ }^{1}$, Xiaocheng Zhang ${ }^{1}$, Maosheng Chen ${ }^{1}$, Dengmei Han ${ }^{2}$ \\ ${ }^{1}$ Department of Ophthalmology, Chongqing Aier Eye Hospital, Chongqing 400000, China; ${ }^{2}$ Department of Ophthalmology, Chongqing Aier Mega \\ Eye Hospital, Chongqing 400060, China \\ Contributions: (I) Conception and design: Y Wen, D Han; (II) Administrative support: Y Wen, X Zhang; (III) Provision of study materials: Y Wen, \\ M Chen, D Han; (IV) Collection and assembly of data: X Zhang, D Han; (V) Data analysis and interpretation: Y Wen, M Chen; (VI) Manuscript \\ writing: All authors; (VII) Final approval of manuscript: All authors. \\ Correspondence to: Dengmei Han. Department of Ophthalmology, Chongqing Aier Mega Eye Hospital, No. 288, Nancheng Avenue, Nan'an District, \\ Chongqing 400060, China. Email: dengtaid@126.com.
}

Background: The incidence of dry eye is high after a cataract surgery. However, the clinical efficacy of sodium hyaluronate combined with conventional eye drops for dry eye after cataract surgery remains unclear. The currently available studies were based on small sample sizes, and no systematic review on this topic has been conducted. Thus, a meta-analysis was performed to systematically and accurately evaluate the clinical value of sodium hyaluronate in the treatment of dry eye after cataract surgery.

Methods: English-language databases including PubMed, Cochrane, and Web of Science, and Chineselanguage databases including (CNKI), Wanfang Database, and CQVIP were systematically searched for relevant articles published up to December 31, 2019. The pooled effect size of qualitative data was evaluated with relative risk (RR) and $95 \%$ confidence interval (CI), and the overall effect of the quantitative data was estimated by using weighted mean difference (WMD) or standard mean difference (SMD) and $95 \%$ CI. Randomized controlled clinical trials concerning the use of sodium hyaluronate combined with conventional treatment for dry eye after cataract surgery were included. The quality of the included literature was evaluated by RevMan5.3 software, and the rest of the statistical data were analyzed using the "meta" package of the R3.5.1 software.

Results: A total of 24 articles including 2,177 eyes (1,088 eyes in the combination group and 1089 eyes in the control group) were included. Twelve articles reported the total effective rate after 1 month of treatment $\left(\mathrm{I}^{2}=71 \%\right)$, and the random effects model was used to estimate RR. The total effective rate in the combination group was 1.33 times that of the control group (95\% CI: 1.21, 1.47). Ten articles reported the dry eye symptom score after 1 month of treatment $\left(\mathrm{I}^{2}=92 \%\right)$. The SMD was estimated using the random effects model. The dry eye symptom score in the combination group was significantly lower than that in the control group, with an SMD of -2.98 (95\% CI: -3.69, -2.27). Seventeen articles reported the tear film break-up time (BUT) after 1 month of treatment. As shown in the random effects model, BUT was significantly longer in the combination group than in the control group, with an MD of 2.06 (95\% CI: 1.63, 2.49). Sixteen articles described the scores of a fluorescein (FL) eye stain test after 1 month of treatment. As shown in the random effects model, FL score was significantly lower in the combination group than in the control group, with an SMD of -2.52 (95\% CI: -3.23, -1.81). Eight articles reported the results of Schirmer I test (SIt) after 1 month of treatment. As estimated by the random effects model, the wetting length in SIt was significantly higher in the combination group than in the control group, with an MD of 1.50 (95\% CI: $0.53,2.48$ ). In the elderly population, BUT was significantly higher in the combined group than in the control group, with an MD of 2.97 (95\% CI: 2.47, 3.47); however, the FL score and SIt showed no such significant difference.

Conclusions: For the patients with dry eye after cataract surgery, sodium hyaluronate on the basis of conventional anti-inflammatory treatment is highly effective as it can improve the dry eye symptom score and the results of 3 tests for dry eye. However, high-quality studies are warranted to further investigate the safety of sodium hyaluronate. 
Keywords: Cataract; dry eye; sodium hyaluronate; meta-analysis

Submitted Feb 06, 2020. Accepted for publication Apr 24, 2020.

doi: 10.21037/apm-20-695

View this article at: http://dx.doi.org/10.21037/apm-20-695

\section{Introduction}

Cataract is an age-related disease, with phacoemulsification combined with intraocular lens implantation being its preferred treatment. Although cataract is a curable disease, it is still the main cause of vision impairment worldwide, greatly affecting the quality of life of patients, and a major public health problem in ophthalmology. Dry eye disease it is mainly manifested clinically as fear of wind and light, dryness, burning sensation, foreign body sensation, and blurred vision (1). The etiology and pathological mechanism of dry eye is quite complicated. As a multifactorial disease of the tears and ocular surface. In addition, goblet cell density cannot be recovered within 3 months after cataract surgery, which may be the cause of eye discomfort and dry eye symptoms. The use of anti-inflammatory eye drops before a cataract surgery causes damage to the endometrium; forceful rinsing of the tear film during the surgery leads to an increase in inflammation factors on the tear film; rinsing the surface of the eye destabilizes the tear film and ocular surface; and finally, the corneal incision causes damage to corneal epithelial cells. Local anesthesia and preservatives with local eye drops can also cause ocular surface discomfort after surgery. All these factors contribute to the high incidence of dry eye after a cataract surgery (2). Dry eye brings inconvenience to the patients and lowers their quality of life, and is not conducive to postoperative recovery. Studies have found that sodium hyaluronate, which is often used as artificial tears, has a similar composition to tears. It has good viscosity and can stay on the ocular surface to lubricate it; furthermore, when combined with fibrin, it can accelerate the adhesion and extension of corneal epithelial cells, thus restoring the stability of the tear film and alleviating dry eye symptoms (3). However, the clinical efficacy of sodium hyaluronate combined with conventional eye drops for dry eye after cataract surgery remains unclear. The currently available studies were based on small sample sizes, and no systematic review on this topic has been conducted. Thus, we carried out a meta-analysis on the clinical efficacy of sodium hyaluronate eye drops in treating dry eye after cataract surgery, with an attempt to inform the rational use of this agent in clinical settings. We present the following article in accordance with the PRISMA reporting checklist (available at http://dx.doi.org/10.21037/apm20-695).

\section{Methods}

\section{Literature review}

The English-language databases including PubMed, Cochrane and Web of science were systematically searched by using key words including "Cataract surgery", "Dry eye", "Xerophthalm", and "Sodium hyaluronate" with no limitations to the language of publication. The Chineselanguage databases including (CNKI), Wanfang Database, and CQVIP were systematically searched for relevant articles by using the combinations of Chinese keywords including "Cataract surgery", "Dry eye", and "Sodium hyaluronate". All the relevant articles published up to December 31, 2019 were searched. Meanwhile, the references included in the literature were retrieved through Google Scholar and other sources.

\section{Inclusion and exclusion criteria}

Articles that met the following criteria were included: (I) all the subjects were patients with dry eye after phacoemulsification combined with intraocular lens implantation; (II) the control group received conventional anti-inflammatory treatment; (III) the intervention group was treated with sodium hyaluronate eye drops (combination group) plus the conventional treatment; (IV) the study was carried out in Chinese populations; (V) the design was a prospective randomized controlled trial; and (VI) all patients were treated for 1 month.

The outcome indicators include any of the following: total effective rate, dry eye symptom score (total score of 3 points), tear film break up time (BUT), fluorescein score (FL), and Schirmer I test (SIt).

The exclusion criteria were the following: (I) suffering from dry eye, glaucoma, diabetes, and other conditions before surgery; (II) a retrospective design; (III) animal experiments, reviews, case reports, comments, abstracts, and 
other types of articles; (IV) use of Chinese medicine during the treatment; and $(\mathrm{V})$ inadequate data. Articles that were published both in Chinese and in English were included as well as those studies with the most comprehensive data.

\section{Literature screening and data extraction}

Two researchers independently screened the search results sequentially by title, abstract, and full text using pre-defined inclusion/exclusion criteria. Data extraction and quality assessment were performed using a standardized form. The basic data of the extracted literature included: authors, publication year, age/gender of the research subjects, and the treatment methods of the control group and the combination group. The effective rate was based on the sample size and the effective cases in the control groups and the combination groups. During the analysis of the measurement data, the dry eye symptom score, BUT, FL, and SIt were extracted from the combination group and the control group 1 month after treatment based on the sample sizes, means, and standard deviations. Where substantial differences existed between the 2 reviewers, a third reviewer was appointed.

\section{Quality evaluation of the articles}

The risks of bias were assessed by using the Cochrane tool, which covers 6 domains of bias: (I) selection bias: whether the randomization method was described in detail; and whether the allocation concealment was used; (II) performance bias: whether blinding was used for subjects and researchers, and whether the effective information for judging the use (or not) of blinding was provided; (III) detection bias: whether blinding was applied in the evaluation of results; (IV) attrition bias: whether the withdrawals from a study and their reasons were reported, so as to ensure the integrity of the outcome data; (V) reporting bias: whether the reported and unreported findings could be identified; and f) other biases: whether other sources of bias could be assessed. For each item, we compared the risk of bias assessment in terms of "low", "unclear", or "high" risk of bias (4).

\section{Statistical analysis}

The overall effect of count data was pooled with relative risk (RR) and 95\% confidence interval (CI), and the overall effect of the quantitative data was estimated by using mean difference (MD) or standard mean difference (SMD) and $95 \%$ CI. Before the data were pooled, the $\mathrm{I}^{2}$ statistic was used to quantify the heterogeneity. When $\mathrm{I}^{2}$ was $\leq 50 \%$, a fixed effects model was used, otherwise a random effects model was used. For studies with heterogeneities, the metaanalysis was performed after eliminating the articles one by one to explore whether the existence of a specific article had a greater impact on the results. The subjects were divided into two subgroups (the elderly group and the age-related cataract group) to explore the sources of heterogeneity. Begg's rank correlation and Egger's weighted regression tests were employed to assess the presence of publication bias. A chart of the study quality was made using Revman 5.3 software. The combined effect values, forest plot, publication bias assessment, and sensitivity analysis were based on the "meta" package on $\mathrm{R}$ software version 3.5.1.

\section{Results}

\section{Included articles}

A total of 212 Chinese and English articles were retrieved. According to the inclusion/exclusion criteria, 24 Chinese articles (5-28) entered the final analysis. A flow chart of the study selection process is shown in Figure 1. These 24 articles involved 2,177 eyes (1,088 eyes in the combination group and 1,089 eyes in the control group). The first article was published in 2014, and the vast majority of articles were published in 2017 and 2018. Four articles $(13,14,17,23)$ focused on elderly patients with dry eye after cataract surgery, and the subjects in all the remaining articles had dry eye after surgery for age-related cataracts (Table 1).

\section{Quality evaluation of the articles}

Although 17 of 24 articles reported the use of randomization to avoid patient selection bias, it was unclear whether the performance bias had been considered. Only 1 article (28) reported the use of double-blind method. No article mentioned attrition bias, reporting bias, and other biases. Seven articles $(6,8,16,19,21,25,26)$ were only clinical controlled trials, which were at high risk for selection bias, performance bias, and detection bias. The results of the assessment of risk of bias by using the Cochrane tool are shown in Figure 2. 


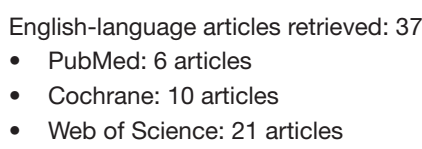

Chinese-language articles retrieved: 342 articles

- CNKI: 82 articles

- Wanfang Database: 182 articles

- CQVIP: 78 articles

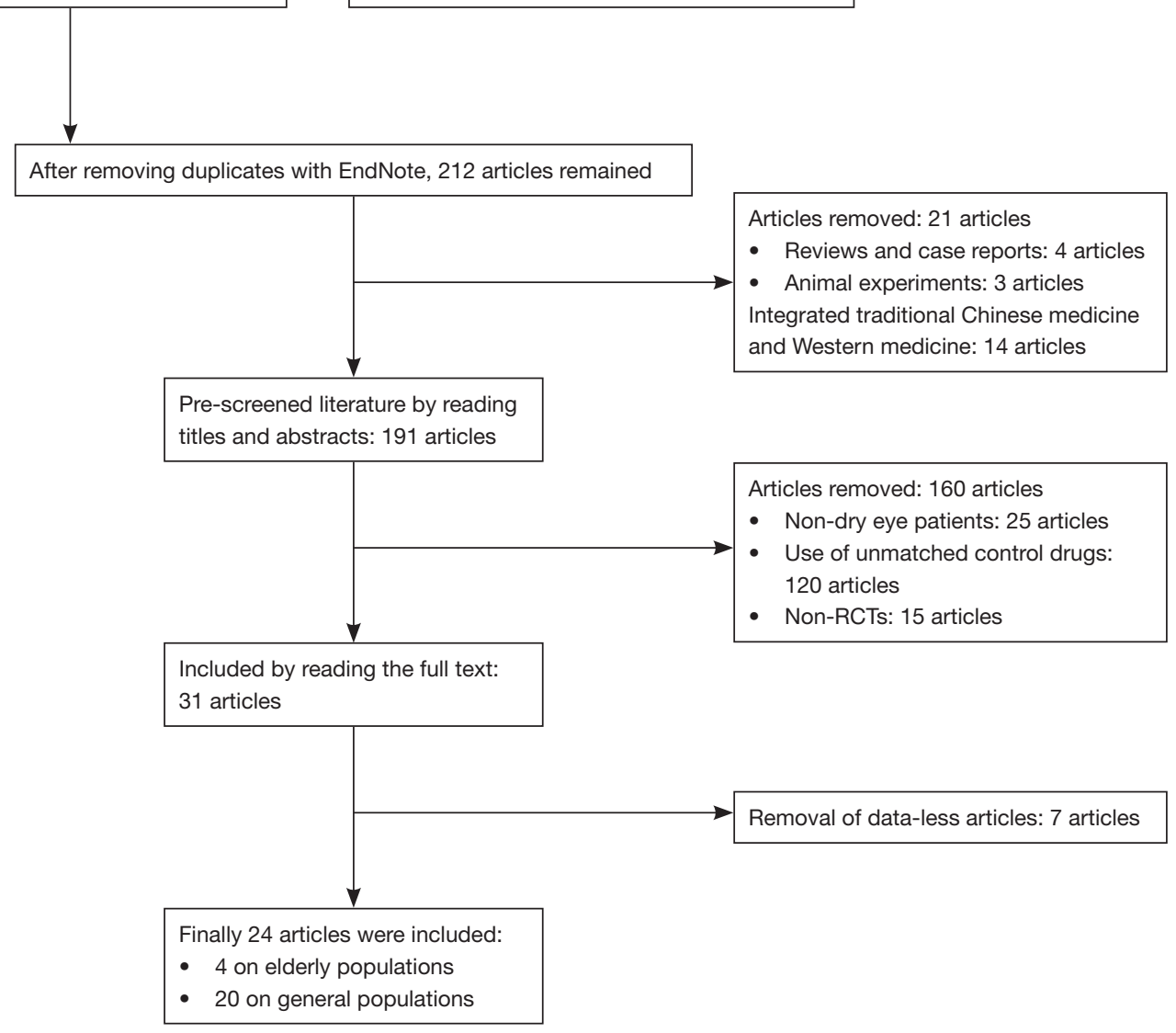

Figure 1 Literature search \& screening flowchart.

\section{Meta-analysis of the effective rate}

Twelve articles reported the total effective rate after 1 month of treatment $\left(\mathrm{I}^{2}=71 \%\right)$, and the random effects model was used to estimate RR. The total effective rate in the combination group was 1.33 times that of the control group (95\% CI: 1.21, 1.47) (Figure 3).

\section{Meta-analysis of dry eye symptom score}

Ten articles ( 1 on the elderly population) reported the dry eye symptom score after 1 month of treatment, with relatively high overall heterogeneity $\left(\mathrm{I}^{2}=92 \%\right)$. The SMD was estimated using the random effects model. The dry eye symptom score in the combination group was significantly lower than that in the control group, with an SMD of -2.98 (95\% CI: -3.69, -2.27) (Figure 4).

\section{Meta-analysis of BUT}

Seventeen articles ( 3 articles on elderly populations) reported the BUT after 1 month of treatment, with relatively high overall heterogeneity $\left(\mathrm{I}^{2}=98 \%\right)$. The MD was estimated using the random effects model. BUT in the combination group was significantly higher than that in the control group, with an MD of 2.06 (95\% CI: $1.63,2.49)$. The elderly populations had relatively low heterogeneity $\left(\mathrm{I}^{2}=28 \%\right)$. The MD was estimated using the fixed effects model. In the elderly populations, BUT in the combination group was significantly higher than that in the 
Table 1 Basic characteristics of the included articles on sodium hyaluronate for dry eye after cataract surgery in Chinese populations

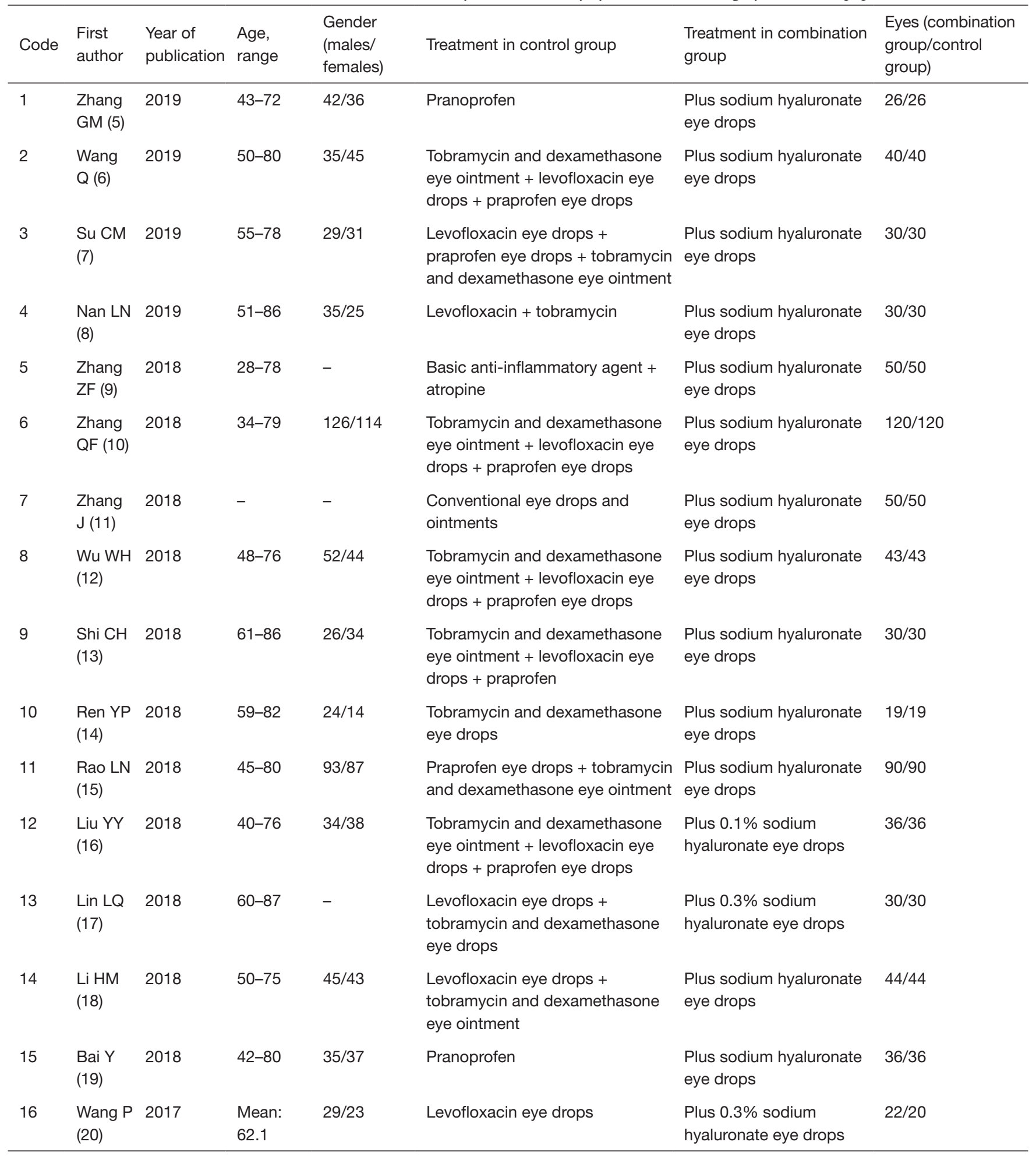

Table 1 (continued) 
Table 1 (continued)

\begin{tabular}{|c|c|c|c|c|c|c|c|}
\hline Code & $\begin{array}{l}\text { First } \\
\text { author }\end{array}$ & $\begin{array}{l}\text { Year of } \\
\text { publication }\end{array}$ & $\begin{array}{l}\text { Age, } \\
\text { range }\end{array}$ & $\begin{array}{l}\text { Gender } \\
\text { (males/ } \\
\text { females) }\end{array}$ & Treatment in control group & $\begin{array}{l}\text { Treatment in combination } \\
\text { group }\end{array}$ & $\begin{array}{l}\text { Eyes (combination } \\
\text { group/control } \\
\text { group) }\end{array}$ \\
\hline 18 & $\begin{array}{l}\text { Lu K } \\
(22)\end{array}$ & 2017 & $48-76$ & $37 / 39$ & $\begin{array}{l}\text { Tobramycin and dexamethasone } \\
\text { eye ointment + levofloxacin eye } \\
\text { drops + praprofen eye drops }\end{array}$ & $\begin{array}{l}\text { Plus sodium hyaluronate } \\
\text { eye drops }\end{array}$ & $38 / 38$ \\
\hline 19 & $\begin{array}{l}\mathrm{Li} \mathrm{HL} \\
(23)\end{array}$ & 2017 & $62-83$ & $36 / 38$ & $\begin{array}{l}\text { Tobramycin and dexamethasone } \\
\text { eye drops }\end{array}$ & $\begin{array}{l}\text { Plus sodium hyaluronate } \\
\text { eye drops }\end{array}$ & $37 / 37$ \\
\hline 20 & $\begin{array}{l}\mathrm{Li} X \mathrm{X} \\
(24)\end{array}$ & 2017 & $45-80$ & $53 / 67$ & $\begin{array}{l}\text { Dexamethasone eye ointment + } \\
\text { praprofen eye drops }\end{array}$ & $\begin{array}{l}\text { Plus sodium hyaluronate } \\
\text { eye drops }\end{array}$ & $60 / 60$ \\
\hline 22 & $\begin{array}{l}\text { Gu YH } \\
(26)\end{array}$ & 2017 & $45-76$ & $47 / 43$ & $\begin{array}{l}\text { Tobramycin and dexamethasone } \\
\text { eye ointment + levofloxacin eye } \\
\text { drops + praprofen eye drops }\end{array}$ & $\begin{array}{l}\text { Plus sodium hyaluronate } \\
\text { eye drops }\end{array}$ & $45 / 45$ \\
\hline 23 & $\begin{array}{l}\operatorname{Ren} Y \\
(27)\end{array}$ & 2016 & $53-81$ & $47 / 43$ & $\begin{array}{l}\text { Routine anti-Inflammatory agent + } \\
\text { praprofen }\end{array}$ & $\begin{array}{l}\text { Plus sodium hyaluronate } \\
\text { eye drops }\end{array}$ & $90 / 90$ \\
\hline 24 & $\begin{array}{l}\text { Chen N } \\
(28)\end{array}$ & 2014 & $50-80$ & $25 / 22$ & $\begin{array}{l}\text { Tobramycin and dexamethasone } \\
\text { eye ointment/eye drops }+ \\
\text { tropicamide eye drops }\end{array}$ & $\begin{array}{l}\text { Plus sodium hyaluronate } \\
\text { eye drops }\end{array}$ & $22 / 25$ \\
\hline
\end{tabular}

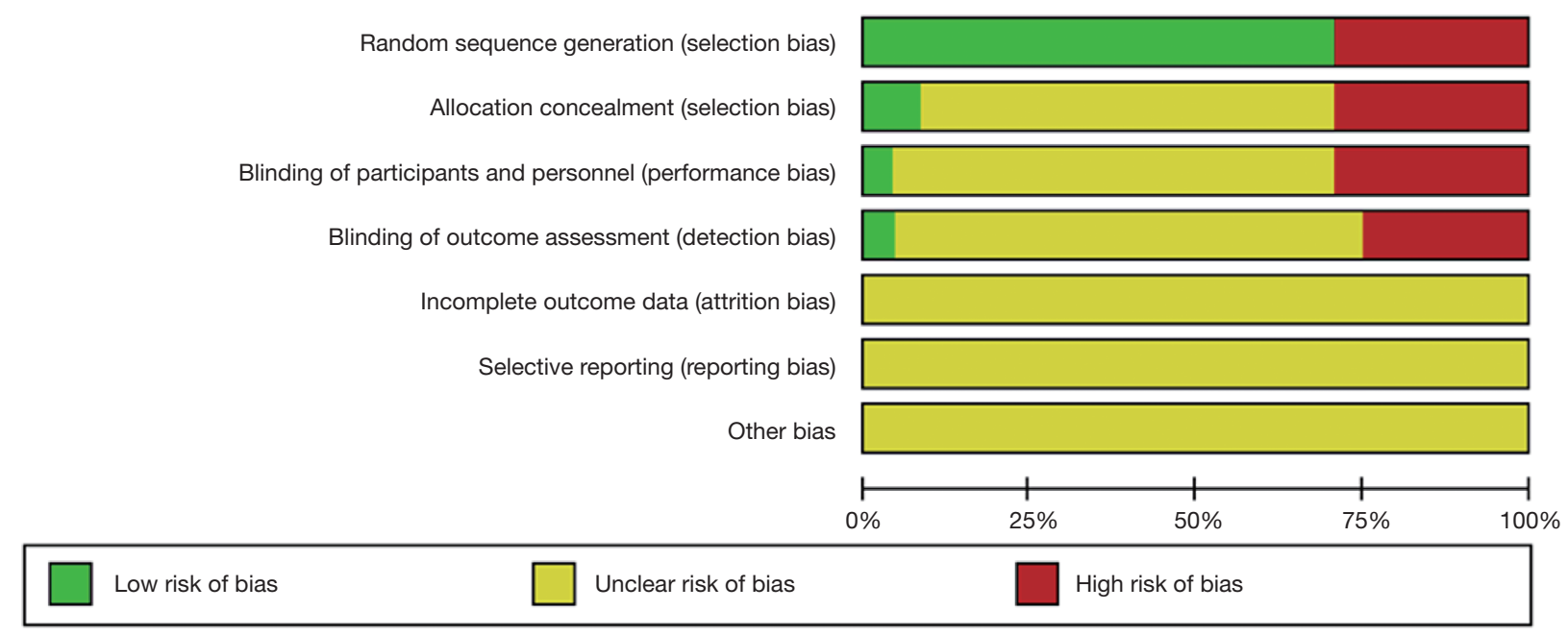

Figure 2 Bias or quality appraisal of included studies.

control group, with an MD of 2.97 (95\% CI: 2.47, 3.47). The elderly populations had relatively high heterogeneity $\left(\mathrm{I}^{2}=98 \%\right)$. The MD was estimated using the random effects model. BUT in the combination group was significantly higher than that in the control group, with an MD of 1.91 (95\% CI: 1.45, 2.37) (Figure 5). 


\begin{tabular}{|c|c|c|c|c|c|c|c|c|}
\hline \multirow{2}{*}{$\begin{array}{c}\text { Study } \\
\text { Nan LN } 2019\end{array}$} & $\begin{array}{l}\text { Experime } \\
\text { Events }\end{array}$ & ental & & $\begin{array}{l}\text { ntrol } \\
\text { Total }\end{array}$ & Risk Ratio & RR & \multicolumn{2}{|c|}{ 95\%-Cl Weight } \\
\hline & 28 & 30 & 23 & 30 & 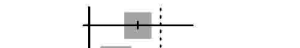 & 1.22 & {$[0.98 ; 1.52]$} & $7.7 \%$ \\
\hline Wang Q 2019 & 39 & 40 & 35 & 40 & + & 1.11 & {$[0.98 ; 1.27]$} & $10.2 \%$ \\
\hline Zhang J 2018 & 50 & 50 & 32 & 50 & 4 & 1.55 & {$[1.27 ; 1.91]$} & $8.1 \%$ \\
\hline Wu WH 2018 & 41 & 43 & 34 & 43 & 1, & 1.21 & {$[1.02 ; 1.43]$} & $9.1 \%$ \\
\hline Zhang ZF 2018 & 45 & 50 & 36 & 50 & $-1:$ & 1.25 & {$[1.03 ; 1.52]$} & $8.3 \%$ \\
\hline Li HM 2018 & 42 & 44 & 36 & 44 & 1, & 1.17 & {$[1.00 ; 1.36]$} & $9.5 \%$ \\
\hline Zhang QF 2018 & 116 & 120 & 62 & 120 & 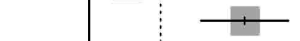 & 1.87 & {$[1.57 ; 2.23]$} & $8.9 \%$ \\
\hline Bai Y 2018 & 35 & 36 & 28 & 36 & 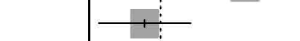 & 1.25 & {$[1.04 ; 1.50]$} & $8.7 \%$ \\
\hline Gu YH 2017 & 45 & 45 & 29 & 45 & $\begin{array}{ll}1 \\
\vdots\end{array}$ & 1.54 & {$[1.25 ; 1.91]$} & $7.8 \%$ \\
\hline Lu K 2017 & 36 & 38 & 28 & 38 & -1 & 1.29 & {$[1.05 ; 1.58]$} & $8.1 \%$ \\
\hline Kuang HM 2017 & 24 & 30 & 15 & 30 & 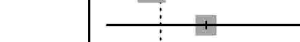 & 1.60 & {$[1.07 ; 2.39]$} & $4.1 \%$ \\
\hline Li XD 2017 & 58 & 60 & 44 & 60 & - & 1.32 & {$[1.12 ; 1.55]$} & $9.3 \%$ \\
\hline \multirow{2}{*}{$\begin{array}{l}\text { Random effects model } \\
\text { Heterogeneity: } I^{2}=71 \%, \tau\end{array}$} & & 586 & & 586 & 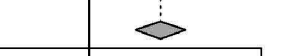 & \multirow[t]{2}{*}{1.33} & {$[1.21 ; 1.47]$} & $100.0 \%$ \\
\hline & & $p<c$ & & & & & & \\
\hline
\end{tabular}

Figure 3 A meta-analysis of the total effective rate of sodium hyaluronate for dry eye after cataract surgery.

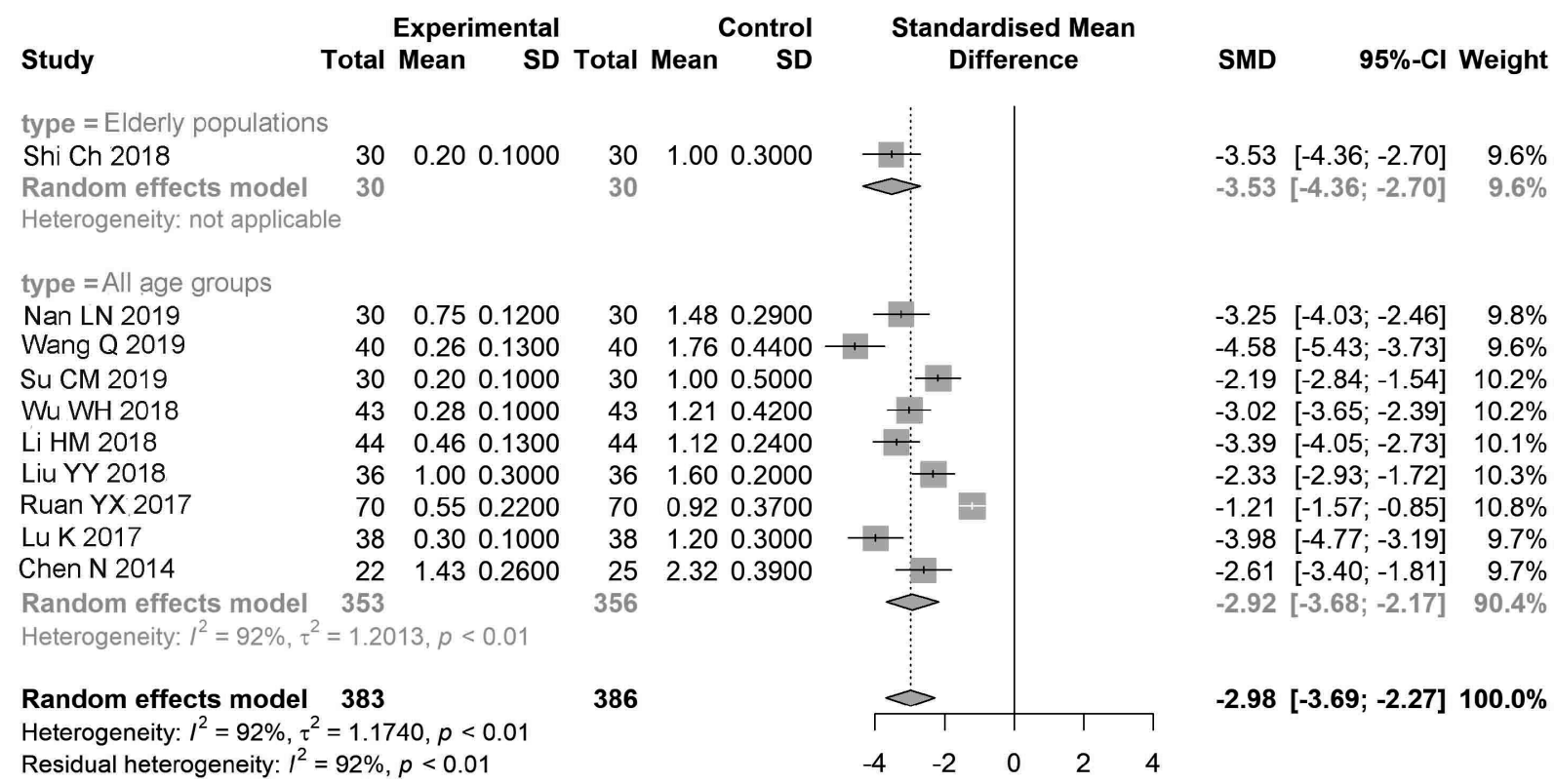

Figure 4 A meta-analysis of the dry eye symptom score in patients treated with sodium hyaluronate for dry eye after cataract surgery.

\section{Meta-analysis of FL score}

Sixteen articles (3 articles on elderly populations) reported the FL score after 1 month of treatment, with relatively high overall heterogeneity $\left(\mathrm{I}^{2}=96 \%\right)$. The SMD was estimated using the random effects model. The FL score in the combination group was significantly lower than that in the control group, with an SMD of -2.52 (95\% CI: $-3.23,-1.81)$. The elderly populations had relatively high heterogeneity $\left(\mathrm{I}^{2}=91 \%\right)$. The SMD was estimated using the random effects model. In this subgroup, FL score showed no significant difference between the combination group and control group, with an SMD of -1.09 (95\% CI: -2.20 , 0.02) (Figure 6). 


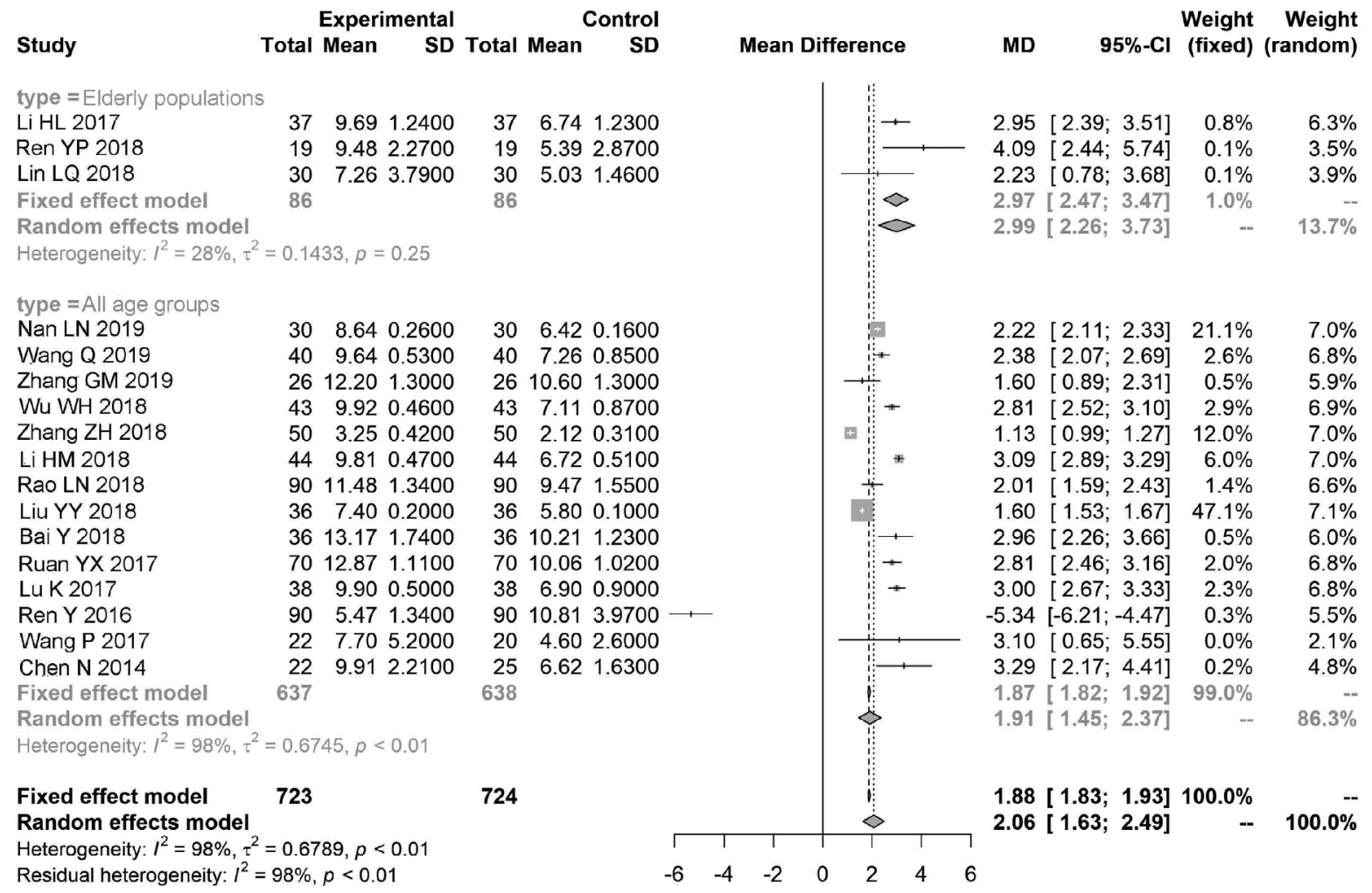

Figure 5 A meta-analysis of the BUT in patients treated with sodium hyaluronate for dry eye after cataract surgery.

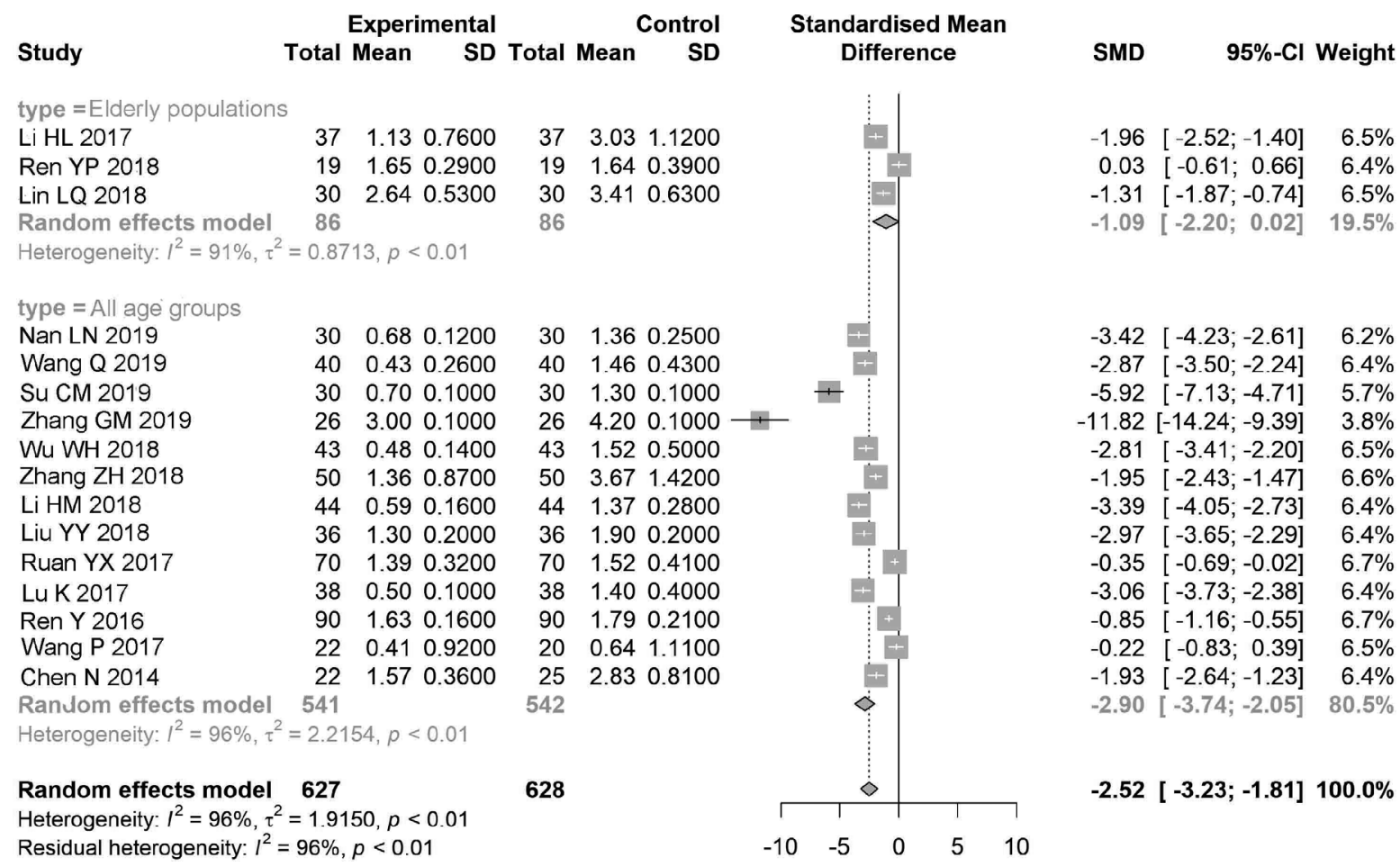

Figure 6 A meta-analysis of the FL score in patients treated with sodium hyaluronate for dry eye after cataract surgery. 


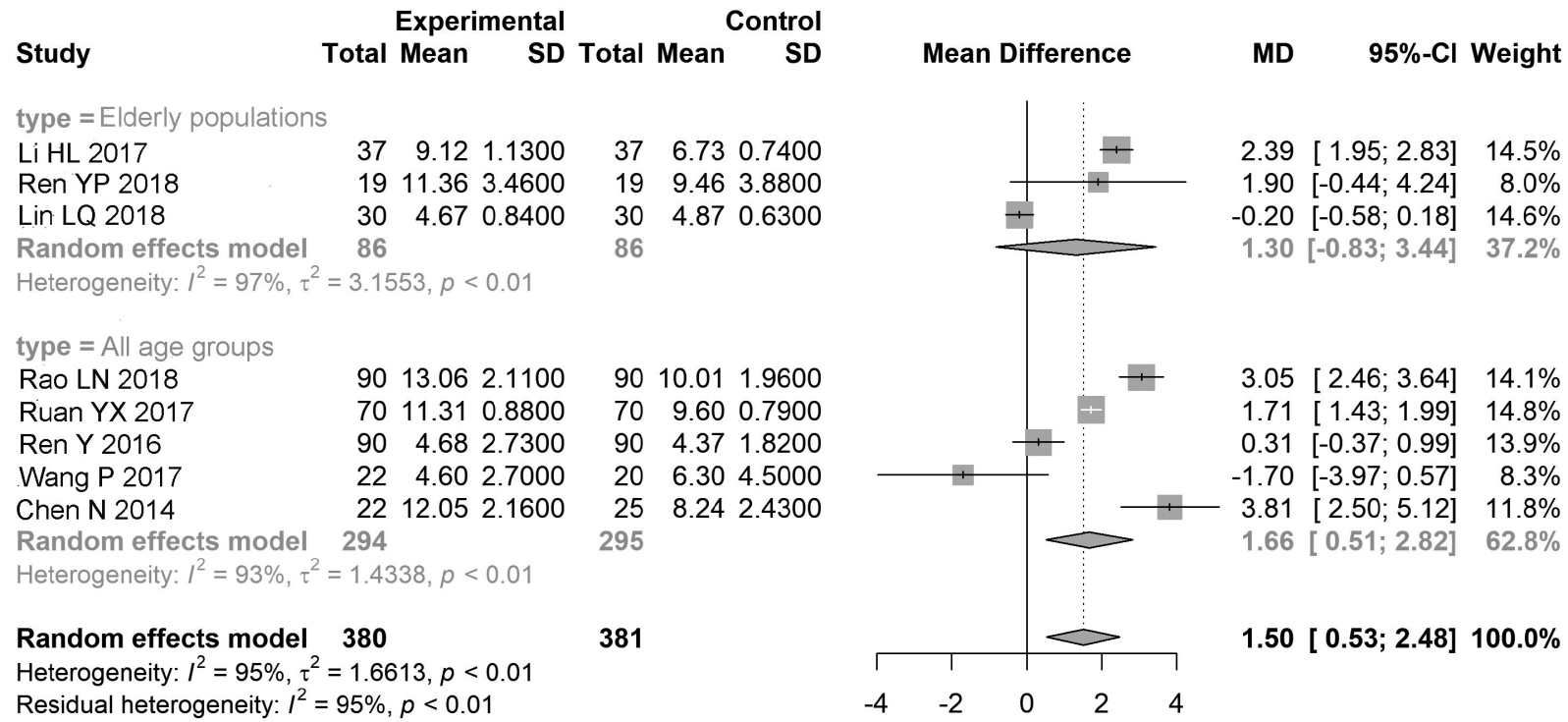

Figure 7 A meta-analysis of the results of SIt in patients treated with sodium hyaluronate for dry eye after cataract surgery.

Table 2 Publication bias in articles on sodium hyaluronate for dry eye after cataract surgery

\begin{tabular}{lccccc}
\hline \multirow{2}{*}{ Items } & \multicolumn{2}{c}{ Egger } & & \multicolumn{2}{c}{ Begg } \\
\cline { 2 - 3 } \cline { 5 - 6 } & $\mathrm{t}$ & $\mathrm{P}$ & & $\mathrm{Z}$ & $\mathrm{P}$ \\
\hline $\begin{array}{l}\text { Total effective } \\
\text { rate }\end{array}$ & 1.649 & 0.130 & & 1.783 & 0.075 \\
$\begin{array}{l}\text { Dry eye symptom } \\
\text { score }\end{array}$ & -1.401 & 0.199 & & -1.163 & 0.245 \\
BUT & 0.869 & 0.398 & -1.648 & 0.099 \\
FL & -0.657 & 0.522 & -1.441 & 0.150 \\
SIt & 0.131 & 0.900 & 0.000 & 1.000 \\
\hline
\end{tabular}

\section{Meta-analysis of SIt}

Eight articles (3 articles on elderly populations) reported the results of SIt after 1 month of treatment, with relatively high overall heterogeneity $\left(\mathrm{I}^{2}=95 \%\right)$. The MD was estimated using the random effects model. The wetting length in SIt was significantly higher in the combination group than that in the control group, with an MD of 1.50 (95\% CI: $0.63,2.48)$. The elderly populations had relatively higher heterogeneity $\left(\mathrm{I}^{2}=97 \%\right)$. The MD was estimated using the random effects model. In this subgroup, FL score showed no significant difference between the combination group and the control group, with a MD of 1.30 (95\% CI: $-0.83,3.44)$ (Figure 7 ).

\section{Sensitivity analysis for publication bias}

Sensitivity analysis was performed after removing the articles one by one, and it was found that the results did not change significantly and remained stable. Egger regression and Begg rank correlation analysis found no publication bias $(\mathrm{P}>0.05)$ (Table 2).

\section{Discussion}

Tear film abnormalities are the main cause of dry eye, and inflammation triggers the development of dry eye and destabilizes tear film (29). Phacoemulsification combined with intraocular lens implantation in cataract patients can affect the function and metabolism of conjunctival cells and destroy the stability of the tear film before, during, and after surgery, leading to the impairment of ocular surface function and the morphological destruction of the tear film lipid layer (26). Ocular surface injury during cataract surgery can increase the level of arachidonic acid. Under the effect of cyclooxygenase, the level of prostaglandin A increases. Both of these aggravate ocular surface inflammation. Meanwhile, postoperative anti-infective eye drops reduce the amount of conjunctival epithelial goblet cells and decrease mucin in tears, leading to a high incidence of dry eye after cataract, especially in elderly patients.

At present, artificial tears can be used to treat dry eye. Sodium hyaluronate is a high-molecular-weight 
polysaccharide composed of repeating disaccharide units of D-glucuronic acid and N-acetyl-D-glucosamine and has the same viscosity, biological tolerance, and elasticity as physiological tears. Sodium hyaluronate mainly acts on the mucin layer of the tear film. By adsorbing a large amount of water and stabilizing the aqueous layer, it can delay the BUT in patients. By binding to fibrin, it promotes the adhesion and extension of the corneal epithelium, forming a protective mesh-like gas-permeable membrane on the eye surface. Also, it can reduce the irritating effect of the drug on the ocular surface tissue, thereby promoting the healing of corneal epithelial injury (30). The subjective questionnaire for dry eye symptoms is often used for evaluating the effectiveness of dry eye treatment. The total score is 3 points, and a higher score means more severe dry eye symptoms. In addition, 3 tests for dry eye are also commonly used indicators for evaluating the efficacy of dry eye treatment: BUT reflects the stability of the tear film, and longer BUT means more stable tear film; Sodium hyaluronate eye drops is a polysaccharide biomaterial. With its good water retention properties, it can slow down the loss of water in the eye, stabilize the aqueous layer, and then delay the tear film tearing time. FL is used to evaluate the integrity of corneal epithelial cells, Sodium hyaluronate eye drops can effectively improve the structure and stability of the tear film of patients; and SIt is used to assess the amount of basal tear secretion. Although the sensitivity of the classification of the severity of dry eye is not high, is an important indicator in the diagnosis of aqueous tear deficiency in dry eye. The storage volume of tears in the conjunctival sac is mainly reflected by the tear river height, and incisions in cataract surgery often damage the limbal nerve fibers, hinder the transmission of neurotransmitters in the nerve fibers around the incision, and cause local corneal perception to decline. The reflex secretion of tears was significantly reduced.

In our current study, patients with dry eye after superemulsification combined with intraocular lens implantation for age-related cataract were treated with sodium hyaluronate eye drops in addition to conventional anti-inflammatory treatment; 1 month later, the subjective score of dry eye was significantly lower in the combination group than in the control group, with an SMD of -2.98 (95\% CI: -3.69 , $-2.27)$ points. The patients had good subjective feeling. However, the subjective score can be affected by various factors, and the definitions of subjective scores were slightly different among different studies. For example, Chen et al. (28) rated the subjective symptoms as 0 if there was never dryness, foreign body sensation, and fatigue, 1 for "occasionally", 2 for "intermittently", and 3 for "constantly". In contrast, Nan et al. (8) defined the subjective symptoms in terms of burning, grittiness/scratchiness, and irritation, and rated the dry eye symptoms as asymptomatic, mild, moderate, and severe on a 0-3 scale. The former was based on the frequency of dry eye, and the latter defined the dry eye symptoms by their severities. Different definitions in the included articles are one of the main reasons for the high heterogeneity in this meta-analysis. Since few studies were performed in the elderly populations, it is not yet possible to derive differences in dry eye symptom scores among the elderly populations.

In our current analysis, as shown in 17 articles, the BUT score after 1 month of treatment was significantly higher in the combination group than in the control group, with an MD of 2.06 (95\% CI: 1.63, 2.49), suggesting the use of sodium hyaluronate after conventional treatment can improve the stability of the tear film and promote the healing of corneal epithelial injury. However, the heterogeneity was high among different studies. Age stratification showed that the elderly populations had low heterogeneity ( $\left.\mathrm{I}^{2}=28 \%\right)$; however, the elderly population was also included in the remaining articles, for which further age stratification was impossible. Notable, BUT was significantly higher in the combination group than in the control group in 14 articles, with an MD of 1.91; in contrast, the MD was 2.97 in the 3 articles focusing on the elderly population. Whether sodium hyaluronate eye drops are more beneficial for elderly patients with cataract warrants further investigation. In our current analysis, the FL score after 1 month of treatment was significantly lower in the combination group than in the control group, with an SMD of -2.52 (95\% CI: $-3.23,-1.81)$. The heterogeneity was high for FL score among different studies. However, the heterogeneity did not decrease after age stratification, which may be related to the inconsistent definitions of FL among different studies. The definition of FL was unclear in Zhang et al.'s study, and high FL scores were presented. In the study performed by Chen et al. (28), the total score of FL was 12 points. In the remaining articles, FL was measured on a scale of up to 3 . In our analysis, the wetting length in SIt was significantly higher in the combination group than in the control group, with an MD of 1.50 (95\% CI: $0.53,2.48)$. The heterogeneity was high for SIt among different studies. However, the heterogeneity did not 
decrease after age stratification. Both FL and SIt showed no significant differences in the elderly populations.

Our analysis demonstrated the remarkable effectiveness of sodium hyaluronate in treating dry eye after cataract surgery. The combined therapy was superior to the conventional anti-inflammatory treatments, as the total effective rate in the combination group was 1.33 times that of the control group (95\% CI: 1.21, 1.47). Therefore, sodium hyaluronate can improve the stability of the tear film, facilitate the healing of corneal epithelial injury, improve the integrity of corneal epithelial cells, and thus optimize the clinical treatment of dry eye. However, due to the differences in effectiveness evaluation criteria among different hospitals and articles, it is not yet possible to perform a stratification-based analysis.

Sensitivity analysis in our current study found that the results of meta-analysis on the effective rate, symptom score, BUT, FL, and SIt were relatively stable, and no single article was found to have a particularly large impact on the results. Meanwhile, Begg's rank correlation and Egger's weighted regression tests showed that there was no publication bias in this meta-analysis; notably, the sensitivity of analysis on publication bias is typically poor when the number of articles is less than 20 (31).

Some limitations of our meta-analysis should be addressed. (I) Most of the included articles were of poor quality. Only 1 article described the use of the double-blind method, and 7 articles did not use randomization. The risks of selection bias, performance bias, and detection bias were high, and the presence of research bias arising from the poor overall quality of these articles cannot be ruled out. (II) The research outcomes had high heterogeneity. In addition to the differences in the definitions of measurement indicators, different population characteristics, reagents, and equipment in different articles might have also contributed to the high heterogeneity. However, stratified analysis is still not possible due to limited data from the relevant populations. (III) The sample sizes in these articles were generally small, especially in the studies focusing on the elderly patients. Finally, (IV) the literature that has comprehensively evaluated the safety of the long-term use of sodium hyaluronate is presently insufficient.

In summary, for the patients with dry eye after superemulsification combined with intraocular lens implantation for age-related cataract, sodium hyaluronate on the basis of conventional anti-inflammatory treatment is highly effective as it improved the dry eye symptom score and the results of 3 tests for dry eye. However, the quality of the currently available research is still low, and high-quality studies with large samples are needed to confirm our findings. In particularly, the effectiveness and safety of the long-term use of sodium hyaluronate need to be further investigated.

\section{Acknowledgments}

Funding: None.

\section{Footnote}

Reporting Checklist: The authors have completed the PRISMA reporting checklist. Available at http://dx.doi. org/10.21037/apm-20-695

Conflicts of Interest: All authors have completed the ICMJE uniform disclosure form (available at http://dx.doi. org/10.21037/apm-20-695). The authors have no conflicts of interest to declare.

Ethical Statement: The authors are accountable for all aspects of the work in ensuring that questions related to the accuracy or integrity of any part of the work are appropriately investigated and resolved.

Open Access Statement: This is an Open Access article distributed in accordance with the Creative Commons Attribution-NonCommercial-NoDerivs 4.0 International License (CC BY-NC-ND 4.0), which permits the noncommercial replication and distribution of the article with the strict proviso that no changes or edits are made and the original work is properly cited (including links to both the formal publication through the relevant DOI and the license). See: https://creativecommons.org/licenses/by-nc-nd/4.0/.

\section{References}

1. Park DH, Chung JK, Seo DR, et al. Clinical effects and safety of $3 \%$ diquafosol ophthalmic solution for patients with dry eye after cataract surgery: A randomized controlled trial. Am J Ophthalmol 2016;163:122-31.e2.

2. Mohammadpour M, Maleki S, Khorrami-Nejad M. The effect of tea tree oil on dry eye treatment after phacoemulsification cataract surgery: A randomized clinical trial. Eur J Ophthalmol 2019. [Epub ahead of print]. 
3. Miháltz K, Faschinger EM, Vécsei-Marlovits PV. Effects of Lipid- Versus Sodium Hyaluronate-Containing Eye Drops on Optical Quality and Ocular Surface Parameters as a Function of the Meibomian Gland Dropout Rate 2018;37:886-92.

4. Higgins JPT, Green S. Cochrane handbook for systematic reviews of interventions version 5.1.0. The Cochrane Collaboration 2011. Available online: http://www. Cochrane-handbook.org

5. Zhang GM. Clinical efficacy of pranoprofen combined with sodium hyaluronate on the dry eye after cataract surgery. World Latest Medicine Information 2019; 19:147,151.

6. Wang Q. Prevention and treatment of dry eye after phacoemulsification. Home Medicine 2019;98-9.

7. Su CM, Liu CD. Clinical analysis and drug treatment of dry eye after cataract surgery. Journal of Baotou Medicine 2019;10:69-71.

8. Nan LN. Clinical efficacy of artificial tear in the treatment of dry eye after phacoemulsification combined with intraocular lens implantation for cataract. Special Health $2019 ; 119$.

9. Zhang ZF, Pan J, Zheng W. Clinical efficacy of medical treatment of dry eye after phacoemulsification combined with intraocular lens implantation for cataract. Chinese Journal of the Frontiers of Medical Science 2018;8:87-8.

10. Zhang QF, Peng B. Comparison of the efficacies of different drugs in treating dry eye after cataract surgery. Clinical Research 2018;26:41-3.

11. Zhang J, Wang DL. Analysis of the efficacies of different treatments for dry eye after cataract surgery. Heilongjiang Medicine and Pharmacy 2018;41:25-6.

12. $\mathrm{Wu} \mathrm{WH}$. Clinical efficacy of medical treatment of dry eye after phacoemulsification combined with intraocular lens implantation for cataract. China \& Foreign Medical Treatment 2018;37:107-8,111.

13. Shi CH. Effectiveness of different drugs in treating dry eye after phacoemulsification for cataract. Contemporary Medicine Symposium 2018;16:126-7.

14. Ren YP, Wang LF, Xiang WL. Prevention and treatment of dry eye after phacoemulsification for cataract with different artificial tears. China Modern Doctor 2018;56:75-8.

15. Rao LN. Value of sodium hyaluronate eye drops in the treatment of dry eye after cataract surgery. General Journal of Stomatology (Electronic Edition) 2018;5:131-2.

16. Liu YY. Effectiveness of different drugs in treating dry eye after phacoemulsification for cataract. Journal of Snake 2018;30:491-2.

17. Lin LQ. Observation on the curative effect of $0.3 \%$ sodium hyaluronate eye drops in the treatment of dry eye after cataract phacoemulsification combined with intraocular lens implantation. Clinical Medicine \& Engineering 2018;25:867-8.

18. Li HM. Clinical study on the treatment of dry eye after cataract surgery. Health Must-read Magazine 2018;107-8.

19. Bai Y. Clinical effectiveness of pramiphene and sodium hyaluronate in the treatment of dry eye after cataract surgery. Journal of Clinical Medical (Electronic Edition) 2018;5:24-5.

20. Wang P, Wu ZH. Effectiveness of sodium hyaluronate eye drops in patients with dry eye after cataract surgery. China Journal of Emergency Resuscitation and Disaster Medicine 2017;12:146-9.

21. Ruan YX, Wang YL, Sun N, et al. Efficacy of different kinds of artificial tears treatment in patients with xerophthalmia after phacoemulsification combined with intraocular lens implantation. Int Eye Sci 2017;17:1705-8.

22. Lu K. Clinical efficacy of medical treatment of dry eye after phacoemulsification for cataract. Journal of North Pharmacy 2017;14:122-3.

23. Li HL, Zhou JW, Zuo W. Effect of sodium hyaluronate eye drops on the structure and stability of tear film in patients with dry eye after cataract surgery. Journal of Taishan Medical College 2017;38:420-1.

24. Li XD. Clinical analysis of sodium hyaluronate eye drops in the treatment of dry eye after phacoemulsification for cataract. Chin J of Mod Drug Appl 2017;11:141-3.

25. Kang HM. Effectiveness of different drugs in treating dry eye after phacoemulsification for cataract. China Prescription Drug 2017;15:90-1.

26. Gu YH, Liu JJ, Chen ZH. Effectiveness of different drugs in treating dry eye after cataract surgery. Contemporary Medicine Symposium 2017;15:151-3.

27. Ren Y. Observation and evaluation of local medication for dry eye after phacoemulsification. Medical Information 2016;29:252-3.

28. Chen N, Xiao W, Liu BT, et al. Comparison on therapeutic effect of hydroxyl-glucoside and sodium hyaluronate on dry eye after age-related cataract surgery. Int Eye Sci 2014;14:1464-8.

29. Yamaguchi T. Inflammatory Response in Dry Eye. Invest Ophthalmol Vis Sci 2018;59:DES192-9.

30. Yoon DY, Kim JH, Jeon HS, et al. Evaluation of the 
Protective Effect of an Ophthalmic Viscosurgical Device on the Ocular Surface in Dry Eye Patients during Cataract Surgery. Korean J Ophthalmol 2019;33:467-74.

Cite this article as: Wen Y, Zhang X, Chen M, Han D. Sodium hyaluronate in the treatment of dry eye after cataract surgery: a meta-analysis. Ann Palliat Med 2020;9(3):927-939. doi: 10.21037/apm-20-695
31. Sterne JA, Egger MSmith GD. Systematic reviews in health care: Investigating and dealing with publication and other biases in meta-analysis. BMJ 2001;323:101-5. 